\title{
Attend to the "Small p" Stuff: State Policy Issues Affecting Cervical Cancer Efforts
}

\author{
Beth E. Meyerson ${ }^{*}$, Carrie A. Lawrence ${ }^{2}$, Jennifer S. Smith ${ }^{3}$ \\ ${ }^{1}$ Rural Center for AIDS/STD Prevention, Indiana University School of Public Health-Bloomington, \\ Bloomington, USA \\ ${ }^{2}$ Indiana University School of Public Health-Bloomington, Bloomington, USA \\ ${ }^{3}$ University of North Carolina-Chapel Hill, Gillings School of Global Public Health, Chapel Hill, USA \\ Email: *bmeyerso@indiana.edu
}

Received 19 March 2014; revised 20 April 2014; accepted 28 April 2014

Copyright (C) 2014 by authors and Scientific Research Publishing Inc.

This work is licensed under the Creative Commons Attribution International License (CC BY). http://creativecommons.org/licenses/by/4.0/

cc) (i) Open Access

\section{Abstract}

Background: States in the United States have primary public health authority. This is the case with cervical cancer, and yet little is known about state policy issues affecting the comprehensive public health response. This study identifies and explores state policy issues affecting cervical cancer efforts in the United States. Methods: Key informant interviews were conducted with a purposeful sample of 15 professionals affiliated with cervical cancer prevention and treatment from national, state and local levels; across sectors: public, private and non-profit; and aspects of the work: screening, treatment and vaccine; program implementation, research, coalition work, and policy. Results: Identified policy issues were administrative and implementation oriented ("small p" policy issues). While participants recognized the importance of laws for vaccine or no cost screening access, the key policy issues preventing successful cervical cancer efforts involved 1) health system complexity; 2) general lack of state level policy, program and funding coordination; and 3) social and organizational cultural issues affecting the adoption of national recommendations and reinforcing program inertia. Conclusions: Understanding state policy issues in cervical cancer is critical for public health success. Dramatic reduction or even elimination of cervical cancer in the United States depends upon the policy work in the "little p" policy areas such as planning and health system organization to affect change. This will require greater leadership and coordination of state efforts across myriad programs. It will require health system improvements, and also the adoption of new practice and program behaviors to capitalize on available technology to reach underserved women.

\section{Keywords}

Cervical Cancer, State Policy, Health System Improvements, State Program Coordination

\footnotetext{
"Corresponding author.
} 


\section{Introduction}

We now have the tools to dramatically reduce cervical cancer in our lifetimes. Prophylactic vaccines against human papillomavirus (HPV) infection are safe and effective [1]-[3]. Diagnostic and screening tools for HPV detection are now available and have been recommended for women $\geq 30$ years [4] [5], and there are treatment options for early stages of cervical precancer or invasive disease. The keys to the success are HPV vaccination, early identification and treatment of pre-cancerous disease. In the United States, significant reductions in cervical cancer have plateaued over the past several years. Women without insurance and women of color face persistent inequities of health access [6]-[8]. This suggests systems-level challenges for our collective attention.

Though the US federal government is omnipresent in public health policy and system organization, states have primary public health authority [9]. States determine vaccine policy, regulate insurance markets, and implement with latitude federal programs such as those under Title X, Vaccine for Children and 317, programs for sexually transmitted disease prevention, and Breast and Cervical Cancer Early Detection Program (hereinafter BCCP but also known as BCCCP). Studies of state policy issues related to cervical cancer have primarily focused on distinct elements of cervical cancer prevention such as vaccination [10] [11], screening [12]-[17] or treatment [18]. These studies provide valuable information about policy issues related to components of cervical cancer approaches, but they do not address the comprehensive effort and associated policy issues. As such, we see cervical cancer through pieces of scattered glass and not through a fully formed policy lens. This study seeks to identify and explore the complexity of key policy issues that span state cervical cancer efforts in the United States.

\section{Methods}

Key informant interviews were conducted with a purposive sample [19] of 15 people working at federal and state levels, across sectors (public/non-profit/private), and across function (policy/research/program) from JuneOctober 2012. Participants were recruited following identification of agencies and organizations matching sample criteria; from review of published and gray literature focused on cervical cancer policy issues; from recommendations by various organizations and individuals affiliated with cervical cancer prevention; and through snowball sampling. The sample was identified to represent the breadth of state policy issues beyond specific programs or focus areas of screening, treatment or vaccination. Potential participants were contacted by email and telephone. Sixty-minute semi-structured interviews were conducted by phone or in person and focused on 10 open-ended questions designed to explore key challenges in cervical cancer, related state policy issues and prioritization, the location of cervical cancer on the state policy agenda and parties involved in state policy issues around cervical cancer. Interviews were recorded and transcribed for a priori coding [20] based on the interview questions and open coding to identify emergent themes. Two investigators independently coded the data to validate theme identification. The study was reviewed and deemed exempt by the Indiana University Institutional Review Board.

\section{Results}

Fifteen people from across sectors and governmental levels participated in the study. State level participants $(46.7 \%, n=7)$ worked either in government programs for women's health, breast and cervical cancer and chronic disease; or in coalitions directly associated with breast and cervical cancer. Federal level participants $(40 \%, n=6)$ were from government programs associated with women's health or cervical cancer, from sexual/women's health and/or cancer related policy organizations, and from associations of state officials and program managers. Sector representation was as follows: public $(26.7 \%, n=4)$, private $(13.3 \%, n=2)$ and non-profit $(60.0 \%, n=9)$. Private sector participants were government relations staff with companies associated with an aspect of cervical cancer prevention (e.g. diagnostics and vaccine).

Table 1 presents the most frequently identified state policy themes related to cervical cancer. Themes included the organization and funding of cervical cancer efforts, system adaptation to reflect new technologies and recommendations, and the policy standing of cervical cancer in planning processes. Issues appeared to group into three areas: 1) health system issues affecting access to vaccination, screening and treatment; 2) state level coordination and 3) social and organizational culture issues. 
Table 1. State policy issues in cervical cancer.

\begin{tabular}{|c|c|c|}
\hline Health System Issues & State Level Coordination & Cultural Elements (socio-organizational) \\
\hline $\begin{array}{l}\text { System Organization } \\
\text { - } \quad \text { System complexity } \\
\text { - } \quad \text { System fragmentation } \\
\text { - } \quad \begin{array}{l}\text { Limited sphere of influence for } \\
\text { coordination }\end{array} \\
\text { System Financing } \\
\text { - } \quad \text { Funding inadequacies } \\
\text { - } \quad \text { Assurance of safety-net funding post } \\
\text { healthcare reform implementation }\end{array}$ & $\begin{array}{l}\text { Fragmented State Effort } \\
\text { - } \quad \text { Federalism and state variation } \\
\text { - } \quad \text { Silos (inter and intra-agency) } \\
\text { - } \quad \text { Lack of policy coordination-legislative, } \\
\text { regulatory, planning and prioritization } \\
\text { Policy Standing of Cervical Cancer } \\
\text { - } \quad \text { Cancer coordination efforts } \\
\text { - } \quad \text { Agenda setting for policy and planning }\end{array}$ & $\begin{array}{l}\text { Stigma } \\
\text { - } \quad \begin{array}{l}\text { Normalizing of vaccination and } \\
\text { gender inclusion }\end{array} \\
\text { - } \quad \text { HPV screening adoption and } \\
\text { movement away from pap smear } \\
\text { - } \quad \text { Policy framing issues } \\
\text { Program and Practice Inertia } \\
\text { - } \quad \text { Reaching underserved populations } \\
\text { - } \quad \text { Adoption of new technologies }\end{array}$ \\
\hline
\end{tabular}

\subsection{Health System Issues}

Health system issues involved how the organization, functioning and financing of public health systems served as barriers to cervical cancer screening and treatment. Themes included system complexities, anticipated health reform, and concern for the healthcare safety net. Funding issues included insufficient funding for safety net programs such as the BCCP program to sustain screening efforts throughout the year, and managing the multiple and complex systems of healthcare financing for women who are eligible for state funded programs.

\subsection{System Organization}

System complexity affected both patients and programs. Participants reported that screening and treatment access was overly complex; requiring significant patient flexibility and a maze of funding arrangements to assure access to follow-up care. Screening involved initial cytology or co-testing with HPV/cytology followed by additional evaluation followed by colposcopy and treatment as necessary; all of which were in separate locations and likely funded or reimbursed differently. Such complexity appeared to be a function of program scope of services and myriad piece-meal funding mechanisms determined by multiple and sometimes conflicting federal and state eligibility requirements. Participants reported that system complexity was compounded by the limited spheres of influence of state cervical cancer programs, such that they did not have influence over eligibility or program services in another state program.

We will pay for the colposcopy, but if that tissue biopsy, if it's found to have cancer, then the patient will go on to BCCP for treatment. Their treatment will be covered until that physician, the oncologist, the surgeon, whomever it may be that's overseeing their care...is no longer doing any type of cancer treatment...The coordination challenges are vast....just in that transition of care. That's not always easy, going from one program to another.

Eligibility conflicts between and among programs and the resulting patient navigation issues were reported as barriers to treatment access and completion. For example, a woman receiving screening services and a diagnosis funded by one program, might not be eligible to receive follow up evaluation and treatment if those services were funded by another program. Participants felt that state programs did not appear to have the range of relationships across their states to mitigate conflicts between and among programs and agencies to establish integrated care. According to participants, programs primarily functioned in silo fashion.

We've had conflict with our program. For example, there are other policies that may relate to the state Medicaid program, and other policies related to the maternal fetal medicine program, and still other policies that are from family planning programs. They all have different state policies that impact the population that they see a little differently.

\subsection{System Financing}

State BCCP are intended to provide the funding of last resort for uninsured women who meet the financial eligibility requirements. BCCP participants noted that demand for screening outpaced program funding, in that they routinely ran out of funds in the third quarter of the grant period. This appeared to be an issue in many states. "Our grant is over in July, but we run out of funds around March." Participants noted that BCCP programs turned away eligible women requiring screening services when resources were exhausted. 
Participants perceived that the Affordable Care Act would increase access to screening and treatment; yet they saw the critical need for safety net funding due to state variability around Medicaid expansion paired with the need to reach underscreened women more effectively. BCCP and Title X funding were seen as critical to assuring a safety net for populations of women who are un/underinsured. The concern was that such funding would be unilaterally deemed unnecessary under healthcare reform by state and federal policy makers.

The BCCP program, while it's not large, does cover a lot of Paps, and Title $X$ does as well.... We know that the Affordable Care Act is going to increase the numbers of uninsured covered; but it's not universal coverage. How do we still make sure that we have a safety net intact to help those women who are still not going to have access to regular insurance?

\section{State Level Coordination}

Participants reported that no state appeared to have a coordinated cervical cancer policy or program strategy to assure continuity of care. While states vary in terms of where cervical cancer related programs reside in government and what they are specifically called, participants indicated that states generally do not coordinate across programs and agencies to improve policy and programs for cervical cancer. Examples of cervical cancer related programs include Breast and Cervical Cancer Early Detection Programs (BCCP), chronic disease programs, women's health programs (e.g. Family Planning, Maternal and Child Health and Women's Health), Sexually Transmitted Disease Programs, Medicaid, high-risk insurance program, Comprehensive Cancer Control Planning, Immunization programs, Primary Care programs and Minority Health. Participants observed that coordination issues might arise in one agency or with one program, but that the agency or program could not control the behavior or coordination efforts of other agencies or programs to address emerging issues. Participants felt that this was due to a paucity of state level leadership in the administrative policy space (executive branch) for cervical cancer.

You have Medicaid in one place and the health department in another, and they're not at all joined. I can't tell you how many times, and it doesn't matter the state, when they will say "Have you talked to the health department?" or if you're talking to the health department, they will ask "Have you talked to Medicaid? Well, could you help us talk with them?" There's a big huge divide in people coming together and what's appropriate for the appropriate health policy.

While states have coordinated mechanisms of planning such as Comprehensive Cancer Control coalitions and plans [20] [21], participants reported that cervical cancer as an issue or program effort did not have much representation or political standing in these processes to address the system issues. The comprehensive planning efforts were often located in a different part of the health department and therefore a creature of siloed functioning. The lack of coordinated strategy to address cervical cancer specifically and the absent sphere of influence to create coordinated systems of care undermined any improvement to cervical cancer efforts. Participants felt that there were generally no identified champions for the cervical cancer effort at state level who could lead the navigation of system improvements in and around comprehensive planning.

There needs to be a champion for it. We're a designated office. However, our funding for the office coming through the state budget is....just not enough to put toward all of the critical issues for women out there. What I'd like to see is some kind of a task force put in place so that everyone's on the same page with cervical cancer. It seems as if we have small projects that are happening through different (funding mechanisms). It just seems siloed. It seems as if it needs to be maybe through a Commission on Women or something. Some forum, state level where priorities can be addressed and everyone can be on the same page for the state priorities.

\section{Cultural Elements: Socio-Organizational}

Socio-organizational elements that were raised involved the role of stigma and how it was expressed in policy and practice. According to participants, stigma served as a barrier to HPV vaccination normalization for girls and boys, and was symbolized by the general lack of inclusion of HPV vaccination on state vaccination schedules. Stigma also played a role in provider and program adoption of HPV testing as standard of care for screening of women $\geq 30$ years. Organizational/cultural issues involved program and practice change to incorporate less frequent screening intervals. Centrally, though, participants recognized the key stigmatizing issue: that a sexually transmitted virus causes cervical cancer.

I think the train left the station on it. I think that we don't really have the luxury any longer of separating cervic- 
al cancer from sex...Cervical cancer is caused by HPV. HPV is a sexually transmitted virus. I think people are more comfortable with messages that lead with cervical cancer, because that's the thing that people should most be worried about, not how they got it, right?

\section{Reaching Underserved Women}

Participants identified the critical need to reach women who were underscreened. This required program, practice and policy changes which participants felt were not easy: providers adopting the new screening recommendations, and programs changing focus to increase their reach of underscreened women. Adopting the recent national screening recommendations for cervical cancer required both program and provider practice change. Program eligibility policy would need to align across programs so that age eligible women can access screening. Participants also felt that success would depend upon the leverage of public and private health care financing for reinforcement; but they were not sanguine about program ability to reinforce the adoption of screening recommendations financially. Some felt that "Medicaid agencies will not pay attention to something as small as cervical cancer" screening when there are other more expensive and competing health issues. Others felt that the federally funded programs such as BCCP, Primary Care (community health centers) and Title X would not change the program requirements to facilitate practice change because provider behavior change would be difficult to achieve or even political.

Cultural issues involved the lack of program practice change to address the evolution of access barriers to screening. Participants discussed the culture of BCCP programs as being primarily that of provider reimbursement with some public education about screening. There was little indication that programs were shifting to adopt new strategies and technologies to improve access for women who do not come to a clinic, such as the addition of outreach HPV self sampling. While not yet approved by the FDA, such sampling was of great interest to some participants.

What we need to do is to push the HPV test as an affordable alternative for the under-screened and medically under-served women. Once we do that, that opens the way for self-collection; and there are at least 3-dozen studies that show that self-collected vaginal swabs and physician collected vaginal swabs yield equal validity in terms of the sensitivity of the HPV test. Every woman can learn to self-collect within 2 minutes or less.

Participants felt that reaching un/underscreened women involved moving toward outreach methods that could be patient controlled and more private. While potentially adding a layer to the screening process, outreach programming with HPV sampling kits might actually reach these women. Such a change would be hard because, according to participants, it required a major shift in mindset about cervical cancer, the populations that need access to screening and follow up, as well as the image of what screening 'should be.' Participants felt that such a shift might yield tremendous results.

If the United States or whoever said self-sampling can be used for outreach [to increase cervical cancer screening], and health plans put a bunch of proven sampling devices in the mail and offered every woman who returned a sample \$20; a lot of things would happen.

Some participants felt that change would be initiated if the policy requirements were shifted. Reimbursement for services according to national recommendations was one example. Another was to increase the BCCP screening program expectations to drive public health innovation.

So the way that (the program) is set up here is with independent clinics who get BCCP reimbursement. I would like for these clinics to spend more time screening never screened women or very rarely screened women. So currently the rule is among women newly enrolled, $20 \%$ of those have to be rarely or never screened...I would like them to do more than $20 \%$. What about $40 \%$ ? What about $50 \%$ ?, since that's where most of the deaths are happening.

\section{Discussion}

Critical state policy issues identified in the study were not "big P" policy issues or laws, but 'small p' policy issues of implementation and unintended systems outcomes. These issues were located in the state administrative policy space. Varied eligibility requirements contributed to system fragmentation, and system alignment appeared to be obstructed by a lack of state level coordination and sphere of influence to make change across state agencies, programs and systems of care. The challenge is further complicated as states face uncertainty around health reform implementation and safety net coverage. According to participants, no one appears to be focused 
on these issues despite their importance.

These "small p" policy issues have generally been off the advocacy radar, because they are complex and often hidden in bureaucratic functioning. However, they are critical to assuring continuity of systems across cervical cancer prevention and treatment arenas. The limited scope of influence among cervical cancer related programs and the paucity of state coordination leadership necessitate advocacy attention to generate movement forward. Public health has a successful history of addressing these more difficult issues, with HIV efforts as case in point. The key is collective action, leadership at the state level and knowledge about how to make these changes. State and local level participants were largely unaware of how to make system change-the partnerships, the mechanisms for change and the political capital that would be necessary for such change. The lack of identified leadership for making system change and leading the state coordinating efforts for cervical cancer was the most troubling finding from a policy change standpoint, particularly due to the appearance of issue intractability.

\section{Conclusions}

Cross-agency, statewide planning could streamline systems for comprehensive and coordinated funding and policy, but we must first address the critical state leadership vacuum for cervical cancer efforts. Increasing the policy acumen and skill set of cervical cancer related programs and coalitions could facilitate change navigation. Success at this "small p" policy level will help to make big strides toward removing structural barriers to cervical cancer efforts in the United States.

The United States is fortunate among our peer nations to have health resources that can, when coordinated well, significantly reduce or eliminate population health threats. However, ours is a system with duplicative and uncoordinated efforts that reinforce health inequity. Cervical cancer could easily be added to CDC's list of "winnable battles"; the success of which would mean that we actually achieve significant reduction or even elimination of a cancer within our lifetimes. If there is no vision for a dramatic reduction in cervical cancer when we are so very close, there will be no energy to address what remains the most persistent issues facing our nation.

\section{Support and Conflict of Interest Statement}

This study was supported in part by the Indiana University School of Public Health-Bloomington and an unrestricted gift from Cervical Cancer-Free America. Authors have no reported conflicts of interest related to this research.

\section{References}

[1] Klein, N.P., Hansen, J., Chao, C., et al. (2012) Safety of Quadrivalent Human Papillomavirus Vaccine Administered Routinely to Females. JAMA Pediatrics, 166, 1140-1148.

[2] Goldstone, S.E. and Vucocolo, S. (2012) A Prophylactic Quadrivalent Vaccine for the Prevention of Infection and Disease Related to HPV-6, -11, -16 and -18. Expert Review of Vaccines, 11, 395-406. http://dx.doi.org/10.1586/erv.12.20

[3] Clark, L.R., Myers, E.R., Huh, W., et al. (2012) Clinical Trial Experience with Prophylactic Human Papillomavirus 6/11/16/18 Vaccine in Young Black Women. Journal of Adolescent Health, in Press.

[4] Saslow, D., Solomon, D., Lawson, H.W., et al. (2012) American Cancer Society, American Society for Colposcopy and Cervical Pathology, and American Society for Clinical Pathology Screening Guidelines for Prevention and Early Detection of Cervical Cancer. CA: A Cancer Journal for Clinicians.

[5] Moyer, V.A. on Behalf of the US Preventive Services Task Force (2012) Screening for Cervical Cancer: US Preventive Services Task Force Recommendation Statement. Annals of Internal Medicine, 156, 880-892. http://dx.doi.org/10.7326/0003-4819-156-12-201206190-00424

[6] Rodriguez, M.A., Ward, L.M. and Perez-Stable, E.J. (2005) Breast and Cervical Cancer Screening: Impact of Health Insurance Status, Ethnicity and Nativity of Latinas. Annals of Family Medicine, 3, 235-241. http://dx.doi.org/10.1370/afm.291

[7] Fedewa, S.A., Cokkinides, V., Virgo, K.S., et al. (2011) Association of Insurance Status and Age with Cervical Cancer Stage At Diagnosis: National Cancer Database, 2000-2007. American Journal of Public Health, 102, 1782-1790. http://dx.doi.org/10.2105/AJPH.2011.300532

[8] Sloan-Barnholtz, J., Patel, N., Rollison, D., et al. (2009) Incidence Trends of Invasive Cervical Cancer in the United 
States by Combined Race and Ethnicity. Cancer Causes and Control, 20, 1129-1138. http://dx.doi.org/10.1007/s10552-009-9317-z

[9] Gostin, L.O. (2008) Public Health Law: Power, Duty, Restraint. University of California Press, Oakland.

[10] Schwartz, J.L., Caplan, A.L., Faden, R.R., et al. (2007) Lessons from the Failure of Human Papillomavirus Vaccine State Requirements. Clinical Pharmacology and Therapeutics, 82, 760-763. http://dx.doi.org/10.1038/sj.clpt.6100397

[11] Kim, J.J. and Goldie, S.J. (2008) Health and Economic Implications of HPV Vaccination in the United States. The New England Journal of Medicine, 359, 821-832. http://dx.doi.org/10.1056/NEJMsa0707052

[12] Goldie, S.J., Kuhn, L., Denny, L., et al. (2001) Policy Analysis of Cervical Cancer Screening in Low-Resource Settings: Clinical Benefits and Cost Effectiveness. JAMA, 285, 3107-3115. http://dx.doi.org/10.1001/jama.285.24.3107

[13] Adams, E., Breen, N. and Joski, P. (2006) Impact of the National Breast and Cervical Cancer Early Detection Program on Mammography and Pap Test Utilization Among White, Hispanic, and African American Women: 1996-2000. Cancer, 109, 348-358.

[14] Baker, L. and Chan, J. (2007) Laws Requiring Health Plans to Provide Direct Access to Obstetricians and Gynecologists, and Use of Cancer Screening by Women. Health Services Research, 42, 990-1006. http://dx.doi.org/10.1111/j.1475-6773.2006.00646.x

[15] Boss, L. and Guckes, F. (1992) Medicaid Coverage of Screening Tests for Breast and Cervical Cancer. American Journal of Public Health, 82, 252-253. http://dx.doi.org/10.2105/AJPH.82.2.252

[16] Moore, K. (1992) A Survey of State Medicaid Policies for Coverage of Screening Mammography and Pap Smear Services. Women's Health Issues, 2, 40-49. http://dx.doi.org/10.1016/S1049-3867(05)80136-7

[17] Lantz, P.M., Weigers, M.E. and House, J.S. (1997) Education and Income Differentials in Breast and Cervical Cancer Screening: Policy Implications for Rural Women. Medical Care, 35, 219-236. http://dx.doi.org/10.1097/00005650-199703000-00004

[18] Mariotto, A.B., Yabroff, K.R., Shao, Y., et al. (2011) Projections of the Cost of Cancer Care in the United States: 2010-2020. Journal of the National Cancer Institute, 103, 117-128. http://dx.doi.org/10.1093/jnci/djq495

[19] Weber, R. (1990) Basic Content Analysis. 2nd Edition, Sage Publications, Thousand Oaks.

[20] Rochester, P.W., Townsend, J.S., Given, L., et al. (2010) Comprehensive Cancer Control: Progress and Accomplishments. Ca Causes and Control, 21, 1967-1977. http://dx.doi.org/10.1007/s10552-010-9657-8

[21] Hager, P., Given, L., Redmond, J. and Rogers, K. (2010) Revision of Comprehensive Cancer Control Plans: Experiences Shared by Three States. Ca Causes and Control, 21, 2005-2013. http://dx.doi.org/10.1007/s10552-010-9662-y 